Article

\title{
A Decision Support System for Assessing Trade-Offs between Ecosystem Management Goals: An Application in Portugal
}

\section{Jordi Garcia-Gonzalo ${ }^{1, *}$, Vladimir Bushenkov ${ }^{2, \dagger}$, Marc E. McDill ${ }^{3, \dagger}$ and José G. Borges ${ }^{1, \dagger}$}

1 Forest Research Centre, School of Agriculture, University of Lisbon, Tapada da Ajuda, 1349-017 Lisbon, Portugal; E-Mail: joseborges@isa.ulisboa.pt

2 Research Centre for Mathematics and Applications, Department of Mathematics, University of Évora, Portugal, Largo dos Colegiais 2, 7000 Évora, Portugal; E-Mail: bushen@uevora.pt

3 School of Forest Resources, The Pennsylvania State University, 214B Ferguson Building, University Park, PA 16802, USA; E-Mail: mem14@psu.edu

$\dagger$ These authors contributed equally to this work.

* Author to whom correspondence should be addressed; E-Mail: jordigarcia@isa.ulisboa.pt; Tel.: +351-213653366; Fax: +351-213653338.

Academic Editor: Eric J. Jokela

Received: 14 October 2014 / Accepted: 19 December 2014 / Published: 30 December 2014

Abstract: Cork oak (Quercus suber L.) and holm oak (Quercus rotundifolia) ecosystems are characteristic of Mediterranean forestry in Portugal. Even though cork is the most valuable product, these ecosystems provide multiple products and services. Assessing trade-offs between multiple goals is thus critical for the effectiveness of oak ecosystem management planning. This paper focuses on the development of a decision support system for oak ecosystems' scenario analysis including multiple criteria. It includes an innovative decision support systems (DSS) functionality to assess trade-offs between the criteria that may support negotiation and consensus building between decision-makers and forest stakeholders. Specifically, a module that encapsulates the Feasible Goals Method/Interactive Decision Maps (FGM/IDM) technique is developed for interactive visualization of the Pareto frontier. The Pareto frontier illustrates the degree to which improving one particular criterion requires accepting sacrifices in the achievements of others. It thus provides information about trade-offs between competing decision-makers' preferences. Results are discussed for a large-scale application encompassing over 1 million ha of cork and holm oak forest ecosystems in Southern Portugal. This study demonstrates the potential of the new 
DSS functionality to enhance multi-objective forest planning, namely by facilitating participation by stakeholders and providing transparency to the decision-making processes.

Keywords: scenario analysis; forest management planning; cork oak; multiple-criteria decision-making; participatory planning; forest policy; multiple stakeholders

\section{Introduction}

Mediterranean oak ecosystem management encompasses multiple economic, social, and ecological objectives. Typically, it involves further multiple stakeholders (e.g., large-scale non-industrial private forestland owners, small scale private forest owners, the forest industry, and agricultural regional offices, as well as other non-governmental organizations). Addressing sustainability concerns in Mediterranean oak forest ecosystem management is thus a complex task that requires the integration of diverse data, information, models, and methods. Stimulated by developments in business administration and industry, decision support systems (DSS) have facilitated this integration, thus contributing to the quality and transparency of decision-making in natural resource management [1]. They provide support to solve forestry problems by integrating database management systems with simulation, analytical and operational research models, graphic display, tabular reporting capabilities, and the expert knowledge of scientists, managers, and decision-makers [1].

The more important and most recent developments of DSS in forest management, including examples from North America, Europe, and Asia, have been reviewed recently [2,3]. According to the authors, a basic conclusion that emerges from the review is that the availability of DSS in forest management has enabled more effective analysis of options and implications that alternative management approaches have for all components of forest ecosystems. The case of Mediterranean forest ecosystem management planning is not an exception and several authors have highlighted the contribution of DSS to increase the efficiency and the effectiveness of its business processes [4-11].

Nevertheless, currently available forestry DSSs do not include an explicit functionality to assess the trade-offs between ecosystem management planning criteria. Marques et al. [12] described the typical DSS architecture with a specific reference to Portuguese forest ecosystems. In summary, a typical DSS is a multicomponent system with geographical and vegetation projection functionalities as well as various combinations of models and optimization techniques, supported by Database Management Systems (DBMS) and accessed by spatial and graphical user interfaces [13,14]. The IT environment and DBM have been evolving from stand-alone/MS Access to web-based/.NET or Java/SQL. The methods base may include a freeware solver (e.g., LP Solve, GNU Linear Programming Kit-GLPK), a commercial solver (e.g., CPLEX), or meta-heuristics, such as Simulated Annealing, Genetic Algorithms, Random Search, or other case-specific heuristics. Furthermore, it is designed so that trade-offs between criteria are checked by comparing the outputs from alternative management planning scenarios. This analysis is conducted by checking scenario-specific reports provided by the graphical user interface. Nevertheless, no specific functionality is included to facilitate the assessment of the trade-offs between criteria by forest stakeholders. This prompted research into an approach to integrate an explicit trade-off assessment functionality in multiple-criteria DSS. 
Typically, individual forest stakeholders' decisions reflect unilateral perceptions of the forest sector, often based on imperfect and unshared information [15]. Nevertheless, the lack of acknowledgement of trade-offs between management planning and/or policy analysis criteria may lead to unnecessary conflicts and sub-optimal resources utilization [16,17]. Huang et al. [18] presented a review of multi-criteria decision analysis (MCDA) in environmental problems. They conclude that the dominant methods are the multi-attribute utility theory (MAUT), outranking, and the analytical hierarchy process. However, they acknowledge the limitations and difficulties of these methods. A system that may integrate an explicit trade-off assessment functionality to promote and facilitate negotiation and participation of multiple stakeholders is needed in order to improve and render more transparent the decision making process.

Borges et al. [19] presented an application of the Feasible Goals Method (FGM) technique to approximate the Pareto frontier for a multi-objective problem. The Pareto frontier comprises points that cannot be improved in one criterion without worsening at least the value of one of the remaining criteria. It thus provides the information needed for the assessment of trade-offs between ecosystem management criteria. Borges et al. [19] presented the mathematical formulation and the approach but research on how to integrate this technique into a DSS was not performed. The current research explores the potential of integrating this technique in decision support architectures (e.g., $[6,13])$ to solve multipurpose ecosystem management planning problems. Specifically, it encompasses the development and integration of a module that encapsulates the FGM technique in a forest ecosystem management decision support system to build interactive and animated visualization maps (i.e., decision maps) of the Pareto frontier [20,21]. It further encompasses research on the linkage of this module within the DSS and the design of interfaces with end users. The decision-maker can investigate these animated visualization maps in an interactive way to assess trade-offs between criteria and select an appropriate criteria combination directly in the computer screen. This is especially important in complex ecosystem management problems where multiple decision-makers and stakeholders are involved. The use of this technique in a user-friendly DSS may support negotiation and consensus building between decision-makers and other forest stakeholders. However, this technique has not been implemented in currently available forestry DSSs. In this context, this paper focuses on the development and the demonstration of the potential use of a DSS functionality to assess the trade-offs between ecosystem management planning and/or policy analysis criteria, which may be very useful to facilitate communication, cooperation, negotiation, and information sharing between stakeholders with a wide range of preferences and interests.

A large-scale application encompassing multiple-criteria forest ecosystem management planning scenarios in Alentejo (circa 1 million ha) in Southern Portugal is used for illustrating the potential of the new DSS functionality to support the analysis of trade-offs between criteria (from three to seven criteria) and the selection of forest-level policies that address strategic multi-objective forest planning goals in a Mediterranean forest ecosystem. The paper is structured as follows. First, the case study area is presented (Section 2.1). Second, the architecture of the DSS and its modules are explained in detail (Sections 2.2-2.5). Third, a description of a hypothetical decision situation is presented, along with the case study methodology (Section 2.6). Fourth, the results section (Section 3) illustrates how the DMs may explore the information provided by the DSS in order to make the final decision. Finally, a critical discussion and final conclusions are presented (Section 4). 


\section{Material and Methods}

\subsection{Case Study}

For scenario analysis purposes, an area in Alentejo in Southern Portugal extending over 1 million ha was considered. Cover types in this area are dominated either by cork oak (Quercus suber L.) or holm oak (Quercus rotundifolia). These species may occur in pure or mixed composition, with different spacing and in even-aged or uneven aged stands. The scenario analysis area was inventoried and firstly classified into 23,373 land units according to criteria such as the dominant and the secondary forest species, density, age, and spatial contiguity (Figure 1). As the latter was not relevant for the scenario analysis objectives, these land units were aggregated into 84 strata according to the first three criteria.

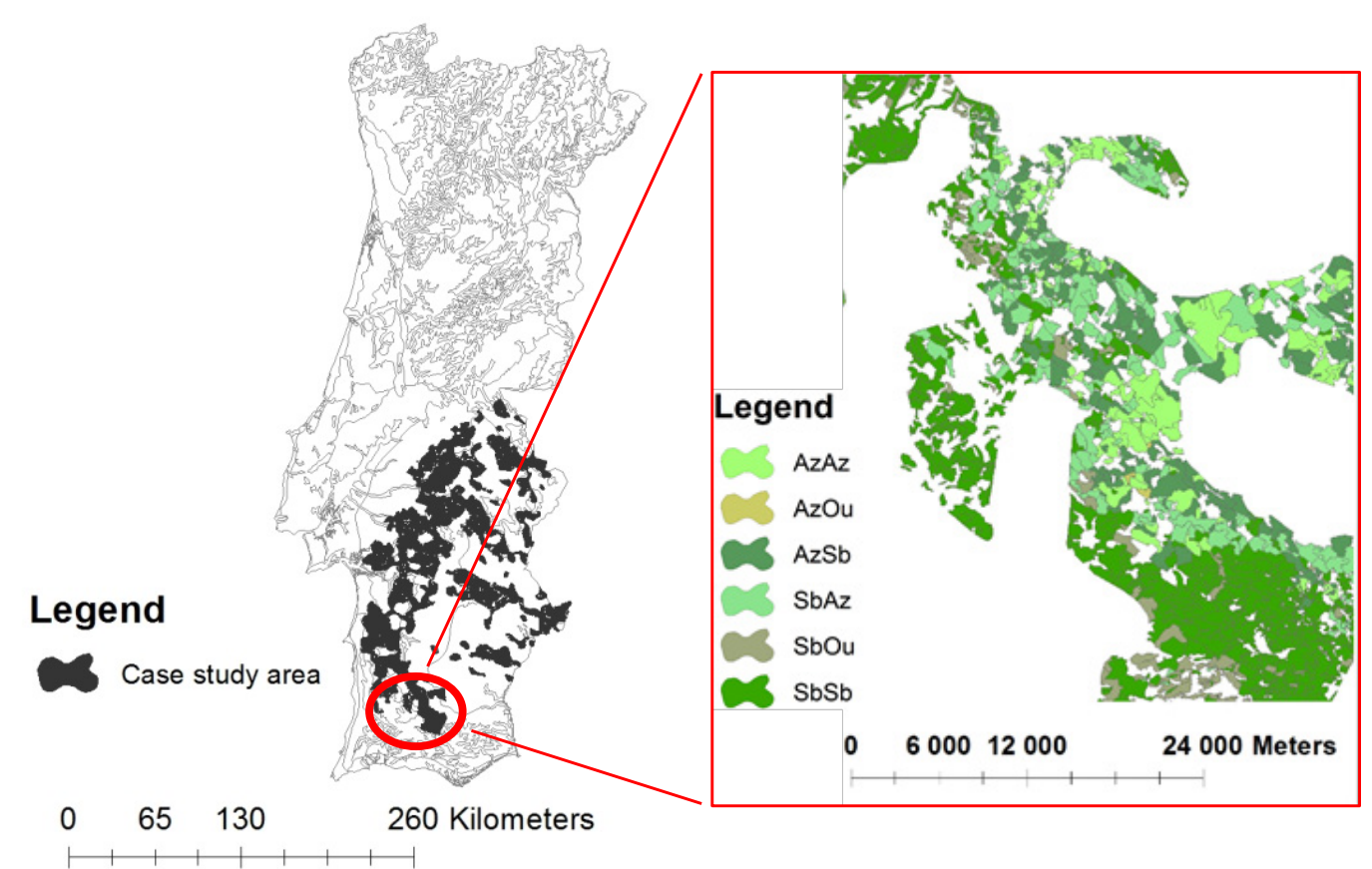

Figure 1. Scenario analysis area in Portugal and example of its spatial heterogeneity. The units shown represent 84 homogenous strata in terms of species composition and density. In this map the colors of the zoomed-in area represent the species composition of the strata where Az refers to holm oak, Sb refers to cork oak and Ou to other species (the first species refers to the dominant species in the strata).

Both cork and holm oak prescriptions encompass thinnings. Most stands are uneven-aged and have densities of 70-150 trees per ha when mature. In the case of cork oak, prescriptions also involve cork extraction. The first debarking cannot take place until the tree perimeter at breast height reaches $70 \mathrm{~cm}$. Thus cork oak debarking usually starts when the age is between 20 and 30 years old. Current legislation further prescribes a minimum tree debarking cycle of 9 years. Thinnings occur in debarking years and remove recently debarked trees. Trees may live up to about 150 years or more.

Cork oak ecosystem management modeling is a particularly complex task, for both tree growth and cork production must be taken into account [6]. In general, this is a multi-objective forest planning problem. In this context, an innovative decision support system (DSS) is developed to address this problem. 


\subsection{Decision Support System (DSS) Architecture}

The new DSS - SADfLOR v $\mathrm{m}$ 1.0 — builds from the previous version of the SADfLOR DSS [6,13] to include the new functionality for oak scenario trade-off analysis. The research reported in the current manuscript builds on the previous SADfLOR structure and includes a new module to encapsulate the Pareto Frontier approach. It includes four independent and compatible components encapsulated in a graphical interface. The first component consists of a management information system. The second component consists of a model base with a vegetation dynamics model [22] and a prescriptions generator. The third component consists of a methods base that was updated to include the new trade-off analysis functionality. It currently encompasses a sub-module that provides multi-objective linear model building functionalities and a sub-module that provides an interactive decision maps building functionality to approximate the efficient frontier of a multiple-criteria planning problem and to analyze trade-offs between the different criteria. The fourth component consists of the report writer (Figure 2).

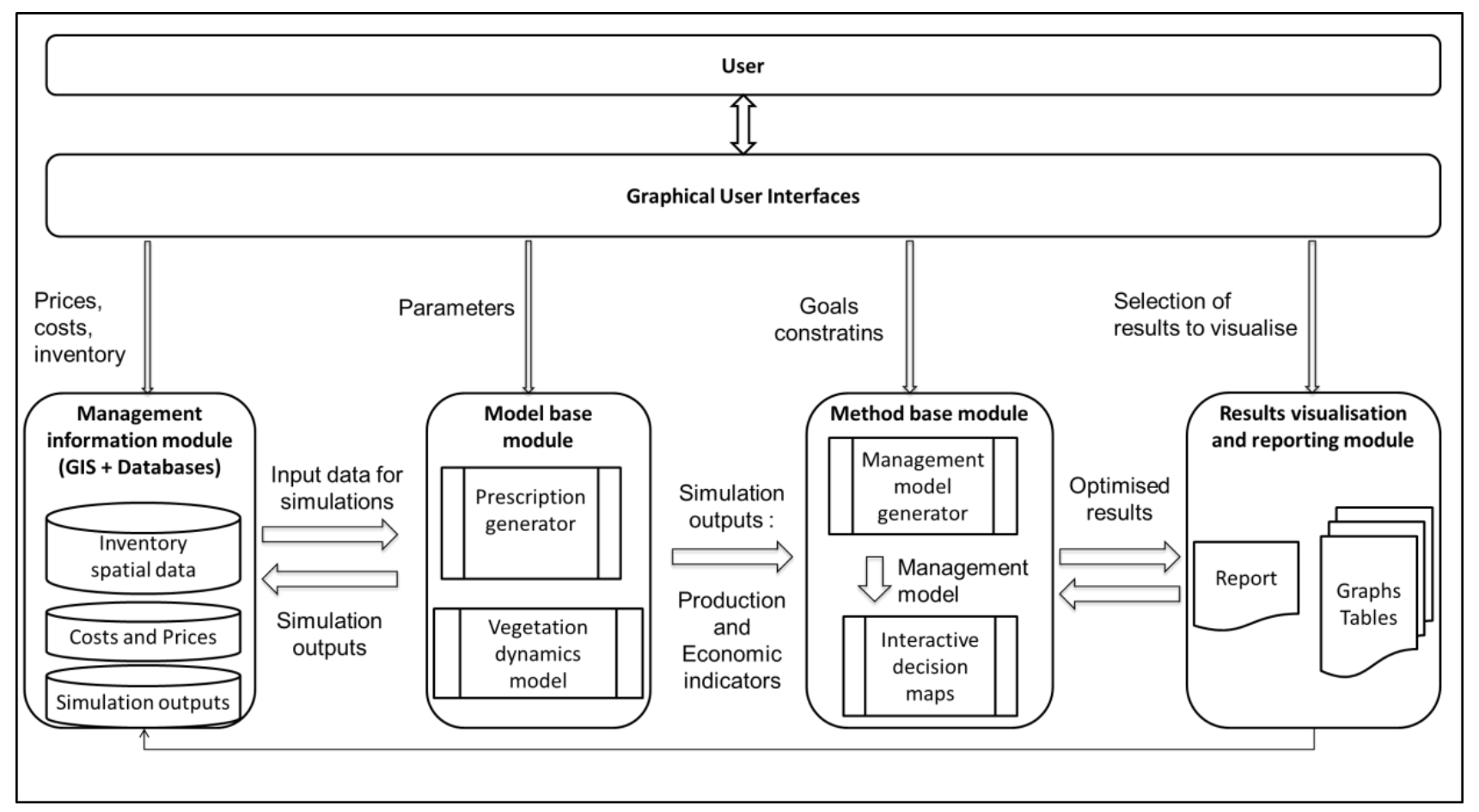

Figure 2. Modules used for solving the multi-objective problem.

\subsection{The Management Information System}

The management information system stores and organizes data from 608 oak plots (3764 cork oak and 1637 holm oak trees) in the 84 strata in the scenario analysis area. The database architecture used in this module follows the INfLOR 2.1 guidelines [14,23]. The freeware MapWinGis stored the strata spatial data. The graphical user interface allows the user to check strata-related information either in the tables or in maps (Figure 3). 


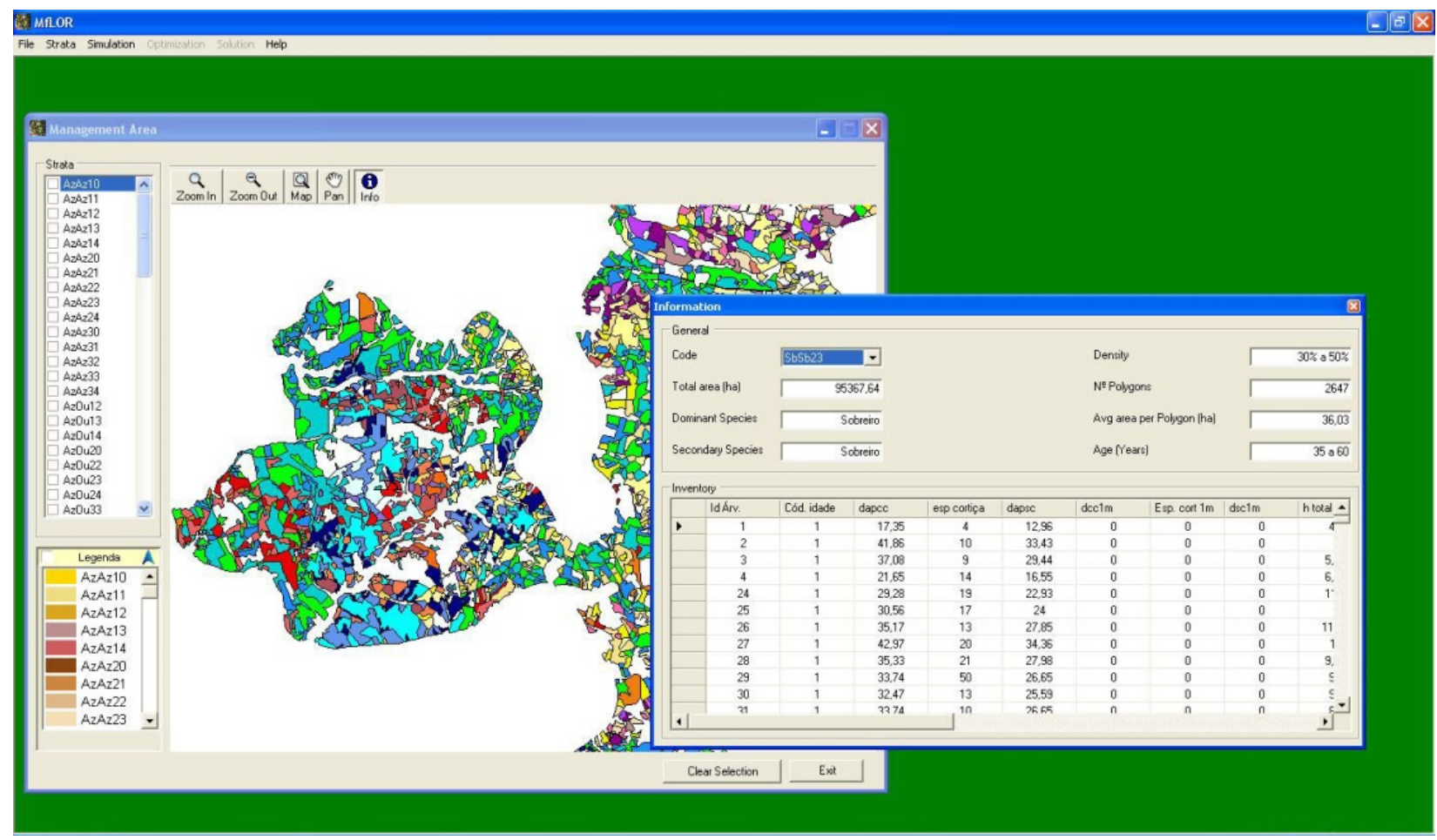

Figure 3. Form to access alphanumeric and geographical data from the scenario analysis area.

\subsection{The Model Base Module with a Vegetation Dynamics Model and a Prescriptions Generator}

The quality of a good DSS depends on the quality of the prescriptions generator [24]. The prescriptions generator is instrumental for building reliable scenarios and policy models. This module integrates a prescription writer and a growth and yield model that allows automated generation for all strata of all data that are pertinent for scenario analysis. Interface with the user is provided through input forms that allow for the specification of simulation parameters and silvicultural practices (e.g., ranges of feasible values for parameters such as debarking cycle). To compute cork and holm oak growth and timber yields, the growth and yield model SUBER v. 4.0 (Instituto Superior de Agronomia, Lisbon, Portugal) is included in the simulation module [22]. It further provides estimates of carbon stocks in the tree above the ground. The structure of the module is flexible and independent from other components of the system in order to allow for updates and changes in the growth and yield simulator without affecting the rest of the system. Thus, the growth and yield models are encapsulated in a FORTRAN executable file that is called by the interactive module developed with the software MS VB.NET (Microsoft Corporation, Redmond, WA, USA). The interface is built upon input forms that allow users to specify simulation parameters and silvicultural practices. The user may define ranges, for instance, for different parameters such as planting density, cork extraction periodicity, and thinning interval to simulate silviculture strategies in all strata.

\subsection{The Methods Base Module with Both Multi-Objective Linear Programming Model Building and Interactive Decision Maps (IDM) Building Functionalities}

The methods base module was updated to include the new trade-off analysis functionality. Therefore, it encompasses two sub-modules, a sub-module that provides multi-objective linear model building 
functionalities and a sub-module that provides an interactive decision maps building functionality to approximate the efficient frontier of a multiple-criteria planning problem and to analyze trade-offs between the different criteria.

\subsubsection{The Methods Base Sub-Module to Provide a Multi-Objective Linear Programming Model} Building Functionality

This sub-module allows the generation of formulations in the linear programming (LP), goal programming (GP), and mixed integer programming (MIP) formats. The model generator reads outputs, comma-separated values (csv) files, from the prescriptions simulator (e.g., harvest volumes) and financial data from the management information module (i.e., interest rate, prices, and costs) and creates the coefficients for all needed equations in the problem formulation. Interface with the user is provided through input forms that allow for the specification of the formulation format, the objective function, and constraints that define the management problem. The structure of the files with the generated matrices was designed to adjust to the requirements of the LP/MIP solvers. This module produces an LP file (LP format) that is read by the Interactive Decision Maps (IDM) sub-module to generate Pareto frontiers of the multi-objective planning problem which allows visualization of criteria trade-off information. This module has been developed with the software MS VB.NET.

2.5.2. The Methods Base Sub-Module to Provide an Interactive Decision Maps (IDM) Building Functionality

This sub-module is used to approximate the efficient (Pareto) frontier of a multiple-criteria planning problem and to analyze trade-offs between the different criteria. This is based on an a posteriori preference modeling method to facilitate the specification of the levels of achievement of various objectives in a typical multi-objective forest management planning framework. This module reads the mathematical formulations developed by the model generator (LP format) and produces Pareto frontiers graphs using the Estimation Refinement Method [25-28].

The module generates the Pareto frontiers as a result of solving a series of auxiliary optimization problems. Currently, the GLPK software package is used to solve these LP models but other solvers could be used. All criteria functions must be added to the model restrictions by the model generator and formulated in the form of special criterion variables. The list of all possible criteria variables can be seen by decision-makers (DMs) at the very beginning of the study (Figure 4). The DMs have the option of restricting some criteria values directly on the screen in interactive mode, without modifying the LP file (Figure 4). The DSS provides information to the user on potentially feasible combinations of values from three to seven criterion values and on efficient criterion trade-offs. He/she also can choose the accuracy of the Pareto frontier description. This module has been programmed in $\mathrm{C}++$.

The Pareto frontiers are visualized as Decision Maps that can be investigated interactively by the user on the interactive interface. The Pareto frontier is thus shown in the form of decision maps, i.e., collections of superimposed bi-criterion slices of Edgeworth-Pareto hull. It displays information on the outcomes of all possible decision strategies in a graphic form (i.e., color pictures). 


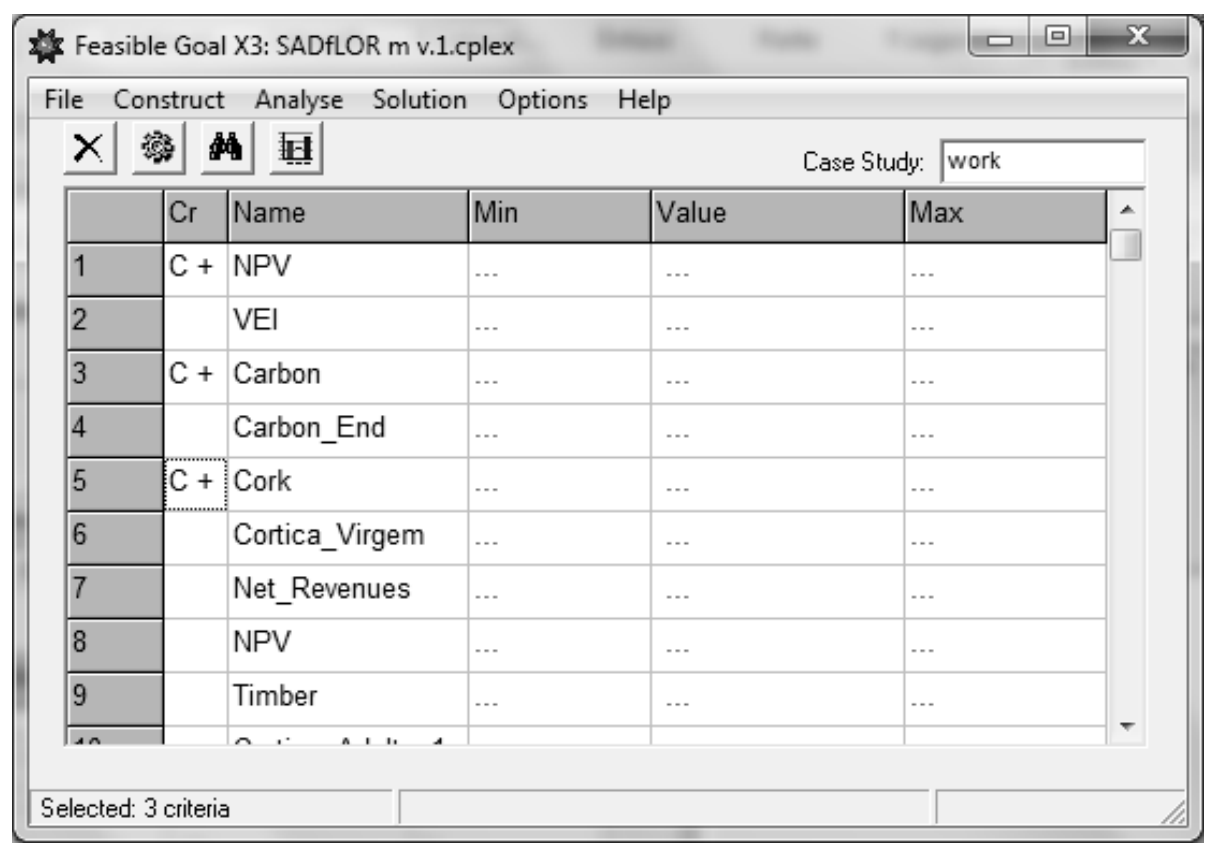

Figure 4. Form to select which trade-offs to analyze and to restrict some criteria values directly on the screen in interactive mode, without modifying the LP file.

The interactive decision maps illustrate in a graphical form the degree to which improving one particular criterion requires accepting sacrifices in the achievements of others (i.e., trade-offs between competing objectives). For example, one may analyze the bi-criteria map where one of the criteria is displayed on the vertical axis and the other on the horizontal axis (Figure 5A). This decision map shows that the maximum amount of timber that can be harvested is almost $55 \times 10^{5} \mathrm{~m}^{3}$, corresponding to a value of $40 \times 10^{7} \mathrm{~kg}$ of cork. If one follows the edge of the map to the direction corresponding to an increase of cork (i.e., to the right of the graph, following the horizontal axis) it is shown that carbon may increase up to $62.5 \times 10^{7} \mathrm{~kg}$ of cork without decreasing the amount of timber harvested. One may still want to increase the amount of cork (i.e., moving further to the right in the graph). In this case, the highest amount of cork that can be obtained is $75 \times 10^{7} \mathrm{~kg}$. However, in this case the level of timber would correspond to $30 \times 10^{5} \mathrm{~m}^{3}$. In the case of three criteria, the map colors correspond to slices of the Pareto frontier for different levels of the third criterion. Each slice presents all possible combinations of values for two criteria when the third criterion is bounded by the corresponding value shown in the top of the legend (Figure 5B). In this case the analysis is similar, but the curve (slice of the Pareto frontier analyzed) will correspond to the color assigned to a certain level of the third criterion (i.e., shown in the slider).

In the two-dimensional map (Figure 5A), each point of the curve indicates an efficient combination of levels of achievement of the two criteria shown in the map. Each point is further underlain by the management plan (i.e., a selection of management alternatives for the management units of the study case area) that would result in those levels of achievement. If this point is selected in the graphical user interface, the DSS provides both the management plan and the values of all other criteria included in the management model. In the three-dimensional figure, each point of a specific curve presents the combination of the pair of criteria shown in axes (e.g., carbon and timber in Figure 5B) when the third criterion is bounded by the corresponding value of the color (the values of the third criterion 
corresponding to each color are shown in the slider (Figure 5B)). Section 3 presents examples with more than three criteria.

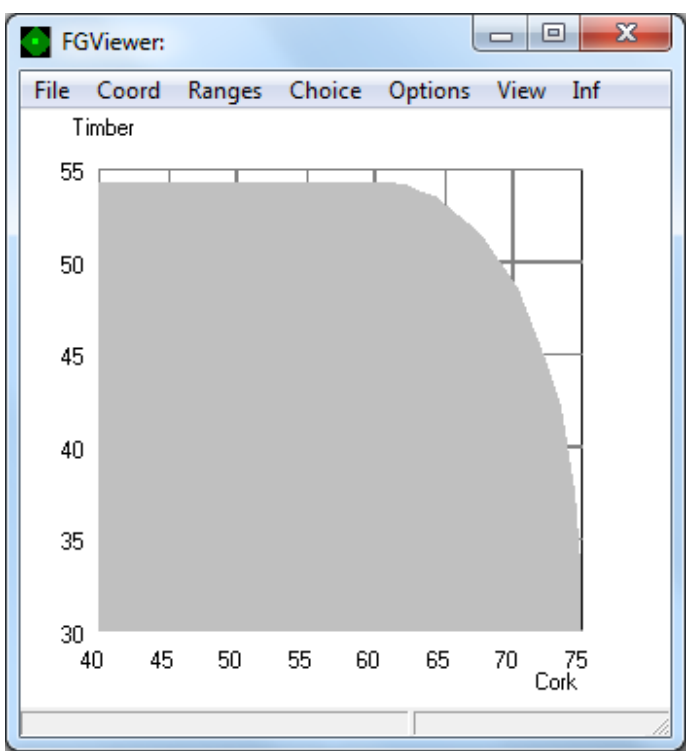

(A)

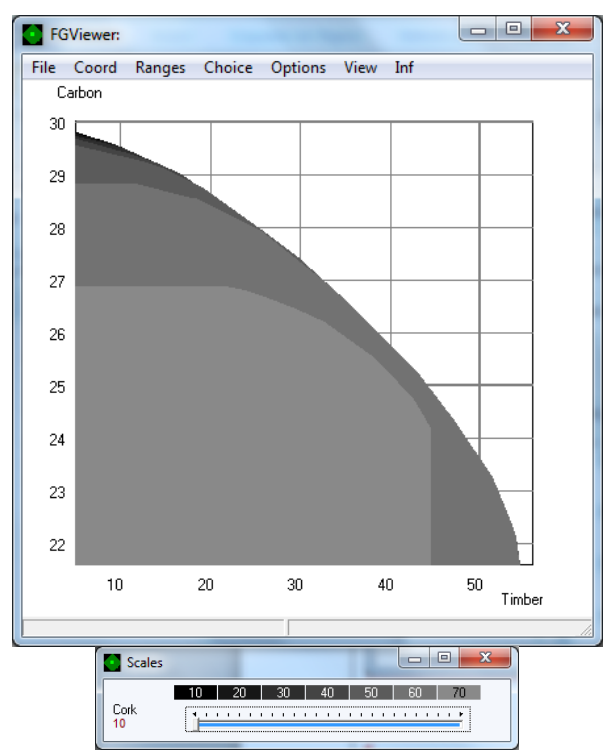

(B)

Figure 5. (A) A two-dimensional decision map displaying the efficient frontier of two criteria; and (B) a three-dimensional decision map displaying the efficient frontier of three criteria. The units of the graph are: $10^{7} \mathrm{~kg}$ of cork, $10^{8} \mathrm{~kg}$ of carbon, and $10^{5} \mathrm{~m}^{3}$ of timber.

In summary, graphic displays of the Pareto frontier help the decision-maker to detect the limits of what is possible and to understand the conflicts between criteria. Thus, the decision-maker has the option to identify and select a preferred feasible combination of criteria values (feasible goals) directly on the graphic display. When the preferable goal (a specific point in the Pareto frontier) is identified, the module provides an associated decision (i.e., decision variables corresponding to the preferable goal), using the Reference Point Method [29]. The decision variables correspond to the selection of management alternatives to apply in the land units.

In summary, the main steps of the Interactive Decision Maps/Feasible Goals Method (IDM/FGM) technique are: (i) construction or approximation of the Pareto frontier, (ii) interactive display of decision maps in the screen, (iii) interactive identification by the user of a preferable feasible goal (i.e., levels of achievement of the different criteria), and (iv) computation of the decision corresponding to this goal. The history of the development and applications of the IDM/FGM technique can be found in [20] and an application in forestry can be found in [19].

\subsection{Case Study Methodology}

For testing purposes we present a hypothetical strategic (i.e., long-term) forest management planning scenario analysis problem where the decision-maker (e.g., the public administration) aims at estimating the regional potential for providing a sustained flow of forest goods and services (e.g., net present value (NPV) of forest activities), timber and cork supplies, and carbon stocks. The DM is interested in setting regional targets and welcomes information about the trade-offs between criteria to help define the targets as well as design a policy to help achieving them. 
Both cork and holm oak growth were simulated using a five-decade planning horizon. The scheme followed for the study (Figure 6) is as follows: First, geographical and biometric data for the 84 strata were stored in the DSS management information system for further use in the simulations. Then prescriptions were generated by the model base. One prescription is a group of cycles and one cycle may encompass one planting density, cork extraction periodicity, and thinning interval. The number of cycles varied from 6 to 27. Simulations by the model base were performed for all prescriptions in all the stands for the full 50-year planning horizon. Economic indicators as net present value (NPV) were calculated, taking into account prices and operational costs from statistical data provided by the Forest Service (using a $4 \%$ discount rate). Information from projections and economic indicators were used to produce the coefficients of the LP management model. The DM/user defined the criteria to analyze (i.e., the objectives of the multi-objective planning problem). The LP model building sub-module in the methods base was then used to generate the multiple objective management planning models. These models were input to the IDM sub-module in the methods base to generate the Pareto frontiers. The DSS allowed the DM to analyze maps and select a combination of levels of achievement of each criterion. After that, the IDM sub-module uses the Reference Point Method [29] to retrieve the corresponding solution in the decision space (i.e., a forest plan) - i.e., it retrieves the prescriptions that may provide that combination of levels of achievement for each criterion. The test problem was solved with a desktop computer (CPU Duo P8400 with 3GB of RAM, Hewlett-Packard Company, Palo Alto, CA, USA).

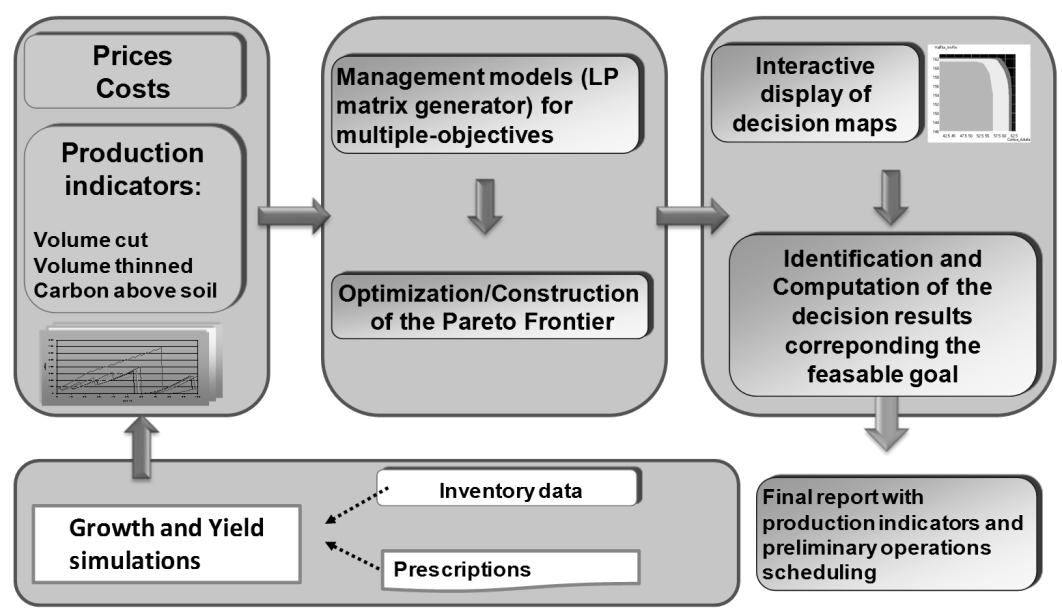

Figure 6. Scheme of the simulation-optimization process.

For scenario analysis purposes, a multi-objective linear model was developed using a typical Model I linear programming (LP) formulation [30]. The model reflects decision-maker policy concerns with the regional forest products and service even-flow. In our study, a decision variable corresponds to the number of ha in stratum assigned to a prescription, i.e., to a sequence of silviculture options that may be implemented in a stratum. The LP model thus encompassed 8400 decision variables to provide both the feasible set in the decision space and the feasible set in the criteria space. The latter provides the information needed by the DM to assess the regional potential and setting regional targets. The former links these targets to the forested landscape from which they derive. The reader is referred to [19] for a detailed description of the LP model. 


\section{Results}

A preliminary analysis maximizing net present value without using regularity constraints revealed that the total NPV (including soil expectation value) for the study area was $79.6 \times 10^{8} €$ over the 50-year planning horizon. Achieving this total income resulted in wide fluctuations of cork production (e.g., up to $100 \%$ in the last period). The maximum value for carbon was $30 \times 10^{8} \mathrm{~kg}$ and for cork yield it was $74.58 \times 10^{7} \mathrm{~kg}$.

The system generated trade-off information for the multi-objective test problem. The interactive decision maps module produced several bi-criteria maps (Figure 7). These maps showed that NPV and total adult cork production were mostly complementary objectives and only competed at very high cork production levels (Figure 7A). So it was almost possible to find an optimum value for both criteria. For this reason, for further constructions of frontiers with more objectives the DM used either NPV or cork. On the other hand, cork and timber are competing objectives as well as carbon and wood, and carbon and NPV, showing a trade-off curve.

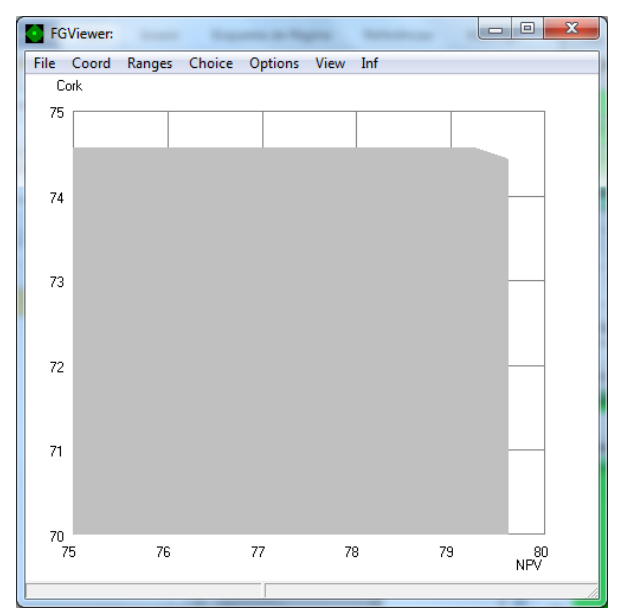

(A)

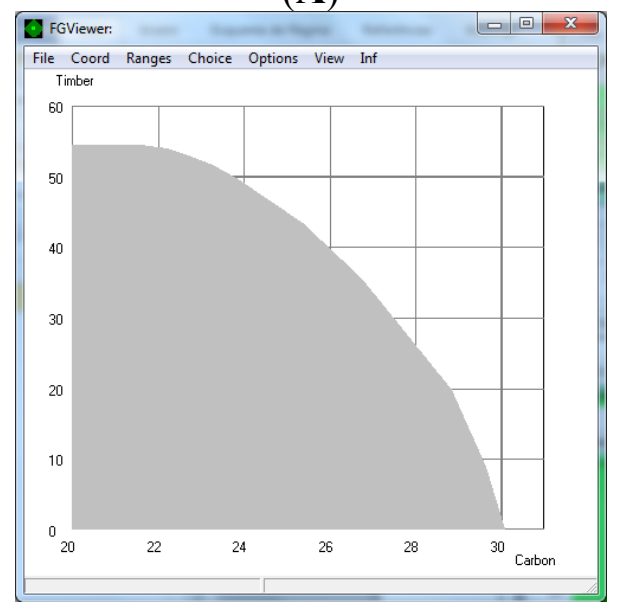

(C)

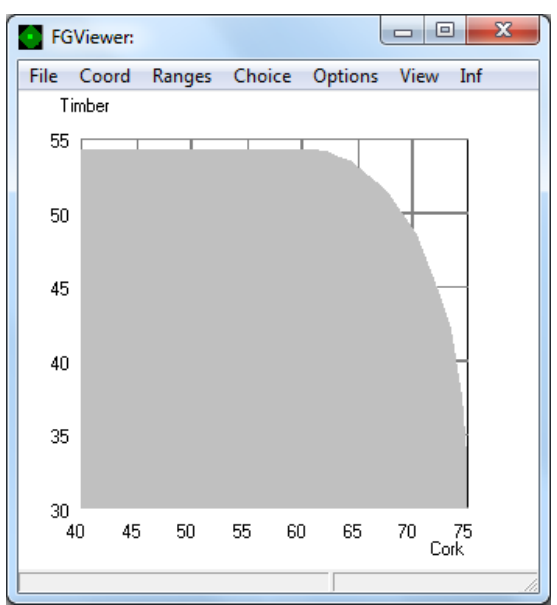

(B)

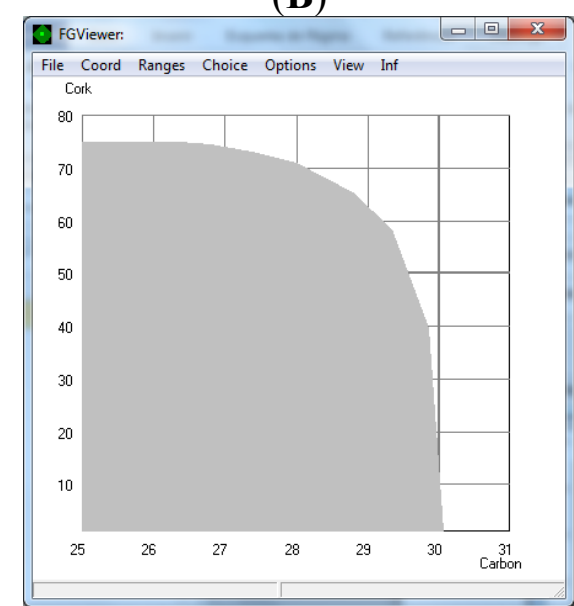

(D)

Figure 7. Two-dimensional decision maps displaying the efficient frontier of our planning problem without considering regularity constraints. The figure shows the trade-off between: (A) cork supply and net present value, (B) timber yield and cork supply, (C) timber yield and carbon stock, (D) cork supply and carbon stock. The units of the graph are: $10^{7} \mathrm{~kg}$ of cork, $10^{8} €$ in the case of NPV (net present value), $10^{8} \mathrm{~kg}$ of carbon, and $10^{5} \mathrm{~m}^{3}$ of timber. 
The trade-off information highlighted the competitive feature of the relationship between timber yield and cork supply (Figure 7B) as well as between the net present value and the carbon stock criteria (Figure 7C). Carbon increased up to $27.6 \times 10^{8} \mathrm{~kg}$ for lower values of NPV. The relation between cork and carbon was not so competitive (Figure 7D) as cork extraction does not lead to the removal of the tree.

When the solutions were constrained to a certain level of regularity of cork availability (allowing the cork production to fluctuate between certain levels among periods) a decrease in both cork production and NPV was observed. The more regularity was sought, the more reduction in both criteria. In this context, when constraining carbon and wood and cork yield fluctuations to a maximum of $30 \%$ between periods, NPV decreased from around $80 \times 10^{8}$ to $75.3 \times 10^{8} €$ and cork yield decreased from around $75 \times 10^{7}$ to $71.5 \times 10^{7} \mathrm{~kg}$. As there was not much difference between the unconstrained solutions, a more strict regularity constraint was tested (Figure 8A,D). Nevertheless, cork even-flow constraints led to an increase of both the carbon stock and the value of the inventory at the end of the planning horizon.

NPV optimization constrained by a maximum $20 \%$ fluctuation deviation in periodic adult cork supply led to a significant reduction of the NPV (i.e., 10\% compared to that of the unconstrained model). Compared to the unconstrained scenario, a restriction of cork flow fluctuation to a maximum of $20 \%$ increased carbon stock and final inventory at the end of the planning period by $8 \%$ and $15 \%$, respectively. In this case, NPV and cork yield were reduced to $71 \times 10^{8} €$ and $62 \times 10^{7} \mathrm{~kg} \cdot \mathrm{C}$ (Figure 8B,E).

If a $10 \%$ regularity constraint was used, the NPV and cork yield were drastically reduced (up to $40 \%$ ) compared to the potential cork yield. This drastic reduction of incomes was due to the inflexibility in cork management; in this scenario a great part of the area would remain unmanaged in order to accomplish the regularity constraint. This would be highly unreasonable. In addition, as the decision-makers (DMs) are mostly concerned with the total amount of cork supply as well as with its sustainability, it was decided to study the trade-offs between cork yield, wood, and carbon sequestration when the adult cork supply maximum deviation across periods was set to $30 \%$. This was considered an adequate strategic policy by the DMs.

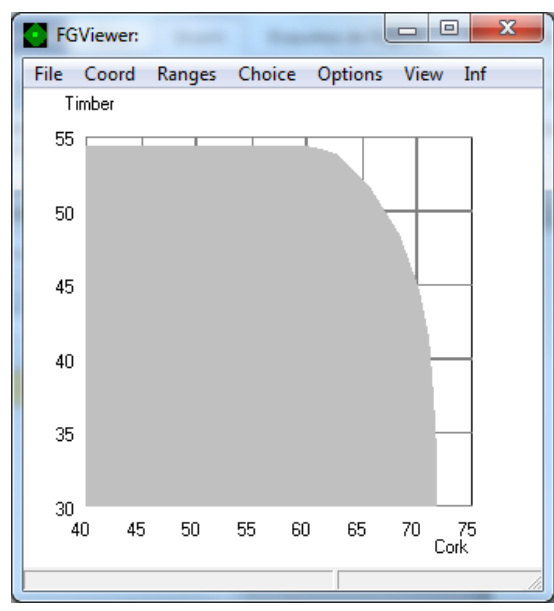

(A)

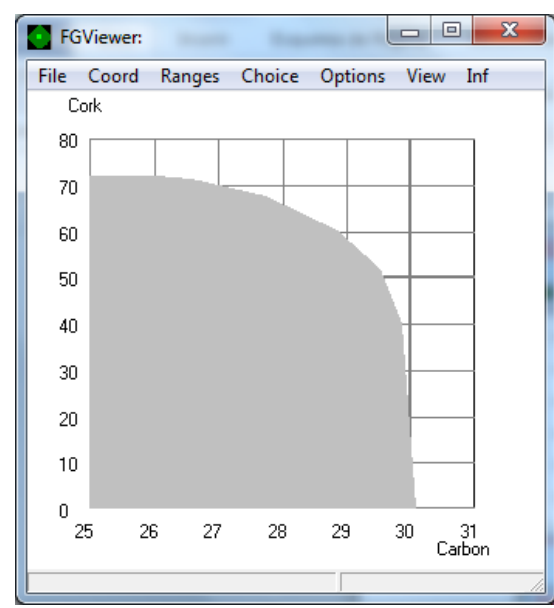

(B)

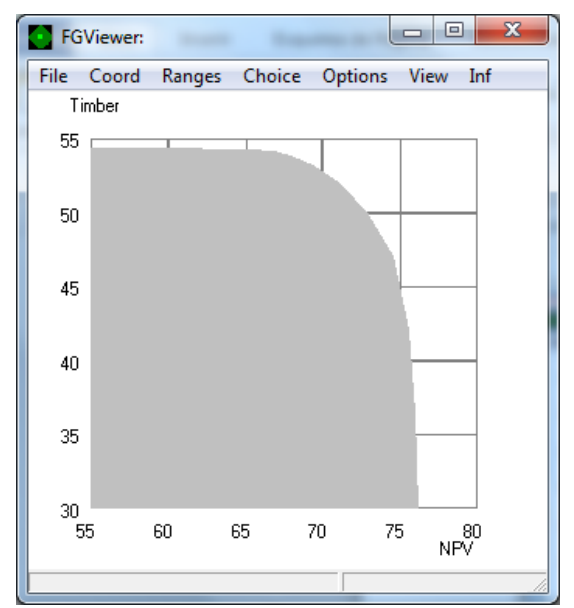

(C)

Figure 8. Cont. 


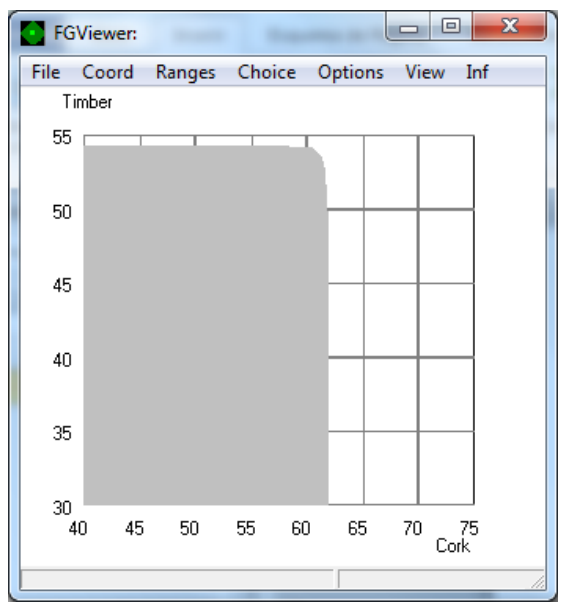

(D)

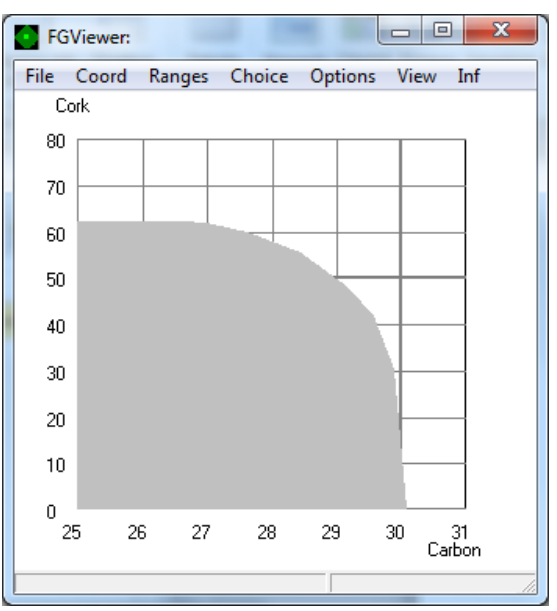

$(\mathbf{E})$

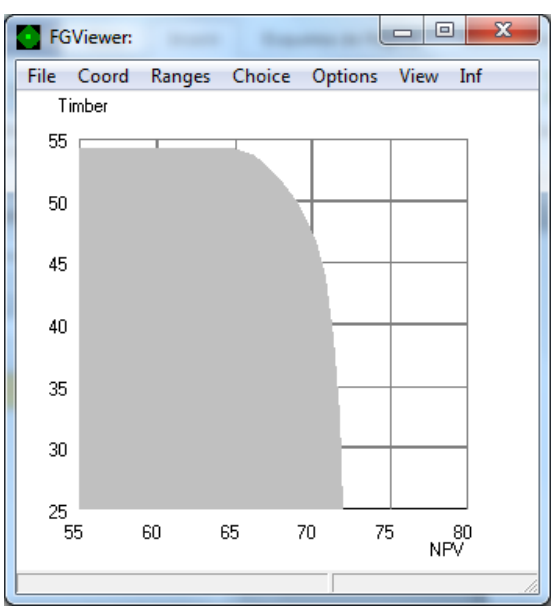

(F)

Figure 8. Two-dimensional decision maps displaying the efficient frontier of our planning problem for the case of $30 \%(\mathbf{A}-\mathbf{C})$ and $20 \%(\mathbf{D}-\mathbf{F})$ adult cork even-flow constraints. The units of the graph are: $10^{7} \mathrm{~kg}$ of cork, $10^{8} €$ in the case of NPV (net present value), $10^{8} \mathrm{~kg}$ of carbon, and $10^{5} \mathrm{~m}^{3}$ of timber.

This was instrumental to generate further information, i.e., the three-dimensional decision maps for various values of total cork supply (Figure 9), for additional trade-off analysis that might help fine-tune the setting of achievement levels.

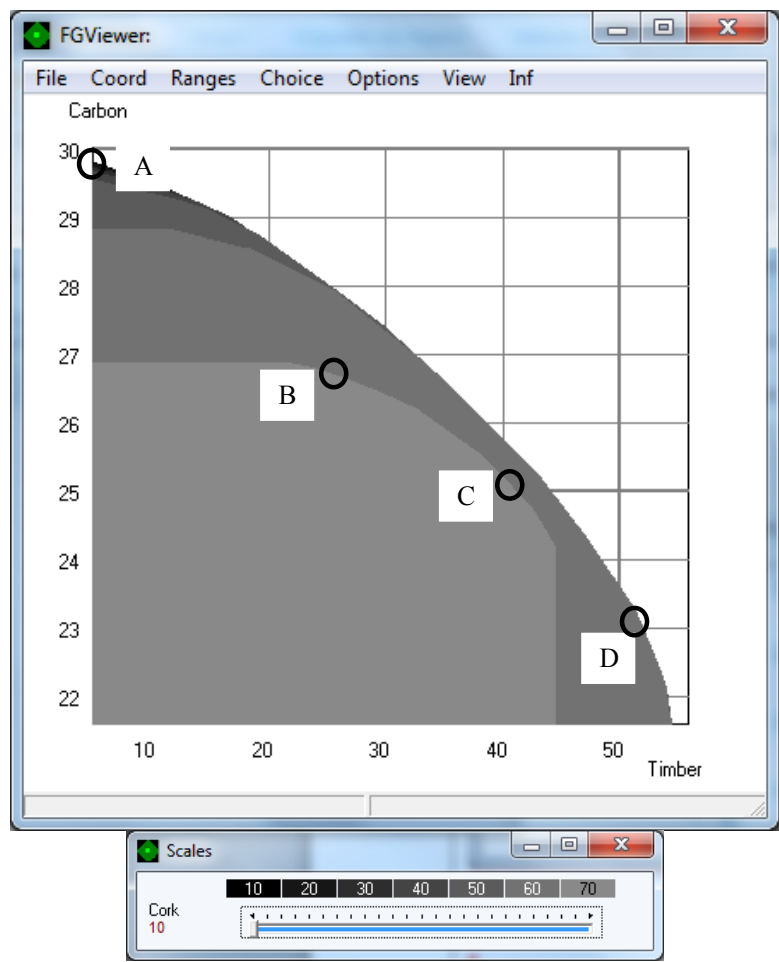

Figure 9. A three-dimensional decision map displaying the efficient frontier of our planning problem under a regularity constraint of $30 \%$ in cork supply. The colored area corresponds to achievement levels of cork supply. Points A-D correspond to points in the Pareto frontiers further analyzed by decision-makers. The units of the graph are: $10^{7} \mathrm{~kg}$ of cork, $10^{8} €$ in the case of NPV (net present value), $10^{8} \mathrm{~kg}$ of carbon, and $10^{5} \mathrm{~m}^{3}$ of timber. 
The trade-off information supported the selection by decision-makers of regions of the Pareto frontier that best reflected their concerns. For that purpose, the methods base sub-module that provides the interactive decision maps (IDM) was used to produce the Pareto frontiers of a three-criteria planning problem (i.e., wood yield, carbon, and cork supply) (Figure 9). This decision map shows timber yield on the horizontal axis, carbon stock on the vertical axis, and cork supply is given by slices in different colors. These colors correspond to different achievement levels of cork supply. The number of slices shown (i.e., levels of achievement) may be modified by the DM directly in the interface. Each slice presents all possible combinations of the pairs (carbon-timber yield) when cork supply is bounded by corresponding values shown in the top of the legend. The decision map clearly shows that wood production directly competes with carbon stock and cork supply (and therefore NPV). The more wood we want to harvest, the less cork is produced. This is the consequence of an increase of harvests from thinning cork oak trees that may not produce adult cork in earlier periods. As a result of removing trees from the ecosystem, less carbon is stored.

Within the decision map for the three conflicting criteria (Figure 9), point A results in the maximum possible carbon stock $\left(29.75 \times 10^{8} \mathrm{~kg}\right)$ but reduces the total cork supply to $15.1 \times 10^{7} \mathrm{~kg}$ and timber yield to $5.72 \times 10^{5} \mathrm{~m}^{3}$. On the contrary, point $\mathrm{D}$ almost maximizes timber yield $\left(51.5 \times 10^{5} \mathrm{~m}^{3}\right)$ with a corresponding cork supply of $60 \times 10^{7} \mathrm{~kg}$ and NPV of $66.2 \times 10^{8} €$, but the carbon (C) stock is drastically reduced to $23.2 \times 10^{8} \mathrm{~kg}$ of $\mathrm{C}$. More interesting points are found in the slice (bi-criterion map) corresponding to the restriction of cork production to $\geq 70 \times 10^{7} \mathrm{~kg}$. Therefore, this first trade-off analysis may provide information to help DMs set minimum achievement levels for three criteria. In its Pareto frontier (trade-off between carbon stock and wood yield), points B and C are further analyzed. Moving from point $\mathrm{B}$ to point $\mathrm{C}$ along the Pareto frontier, carbon stock reduces from $26.8 \times 10^{8} \mathrm{~kg}$ to $24.2 \times$ $10^{8} \mathrm{~kg}$ while timber yield rises from $23.3 \times 10^{5} \mathrm{~m}^{3}$ to $44.3 \times 10^{5} \mathrm{~m}^{3}$. In both cases cork supply is $70 \times$ $10^{7} \mathrm{~kg}$; however, due to higher timber yield, the NPV is higher in point C (i.e., $74.3 \times 10^{8}$ ).

This decision map also shows that the cork supply frontiers are quite close, which means that at a certain level of wood yield small changes in carbon goals will reduce the cork supply drastically (Figure 8). For example, when total timber supply is set to the level found in point B, when C sequestration is slightly increased up to 28 tons, the cork supply obtained is drastically reduced to $50 \times 10^{7} \mathrm{~kg}$ (almost a $25 \%$ reduction). Similarly, if the timber supply is set to $44 \times 10^{5} \mathrm{~m}^{3}$ (the level found in point $\mathrm{C}$ ), when $\mathrm{C}$ stock level is slightly increased to $25 \times 10^{8} \mathrm{~kg}$, the NPV is reduced to $60 \times 10^{8} €$. So for further analysis, DMs may analyze only the area between points B and C; this means that targets for each criterion are set (i.e., cork supply $\geq 50 \times 10^{7} \mathrm{~kg}$, timber yield $\geq 23.3 \times 10^{5} \mathrm{~m}^{3}$, and carbon stock $\geq 24.2 \times 10^{8} \mathrm{~kg}$ ).

In strategic planning, usually in addition to regularity constraints a minimum value for the ending inventory (VEI) is included as a constraint to ensure future production. Therefore, we may further include VEI as a fourth objective. In this case the system generates a four-dimensional decision map considering VEI, cork and carbon stock, and timber. These maps are a sequence of three-dimensional decision maps constructed for different values of e fourth criterion (Figure 10). These parallel figures represent slices of the EPH in the direction of the fourth criterion (i.e., VEI). This decision map shows that VEI competes with both carbon stock and cork supply criteria. The increase in VEI leads to a decrease in both the carbon sequestration and the cork supply. The information provided in the form of these decision maps helped DMs set the target achievement level for the VEI criteria at $156 \times 10^{7} €$. 


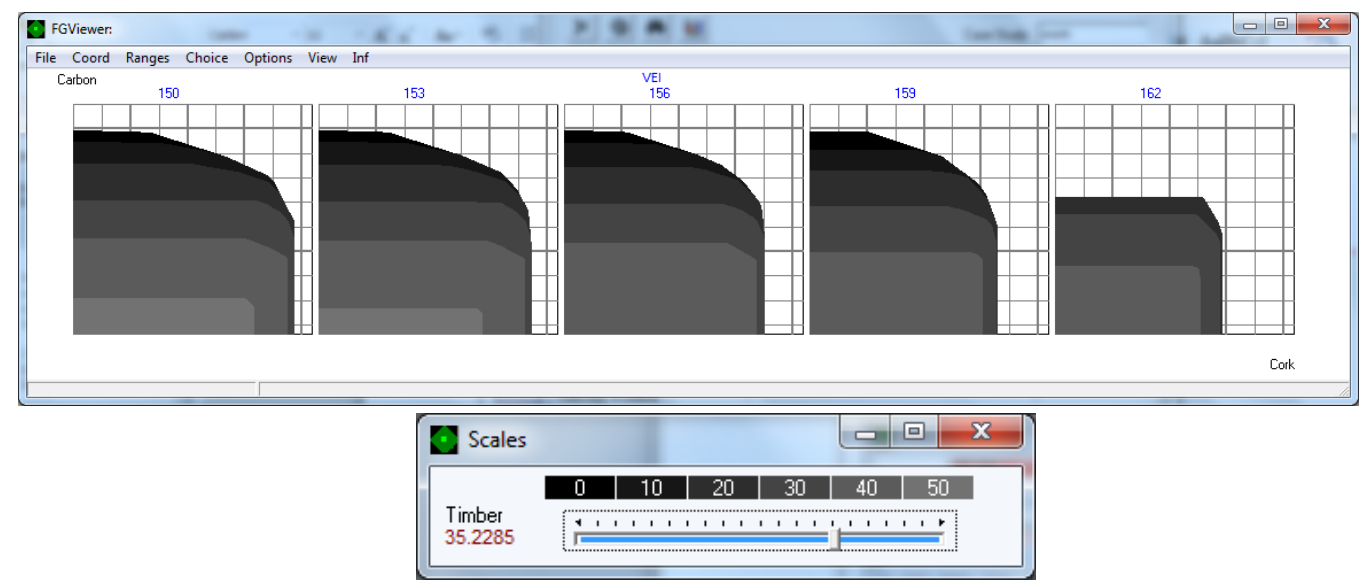

Figure 10. A four-dimensional decision map displaying the efficient frontier of our planning problem under a regularity constraint of $30 \%$ in cork supply, minimum achievement levels for three criteria (targets for each criterion: $\min$ timber $=23.3 \times 10^{4} \mathrm{~m}^{3}$, min cork $=50 \times 10^{7} \mathrm{~kg}$, min carbon $=24.2 \times 10^{8} \mathrm{~kg}$ ). Each decision map corresponds to a specific value for the ending inventory (VEI) of $150 \times 10^{7}, 153 \times 10^{7}, 156 \times 10^{7}, 159 \times 10^{7}$, and $162 \times 10^{7} €$, respectively. The colored area corresponds to achievement levels of timber yield.

For additional trade-off analysis that might help fine-tune the setting of achievement levels, the system may generate a four-dimensional decision maps when setting minimum achievement levels defined in previous steps (Figure 11). In this example, carbon and cork are shown on the axes, NPV is shown in colored slices, and wood yield is shown as the fourth criterion. Therefore, the four-dimensional decision maps consists of sequences of three-dimensional decision maps corresponding to a specific timber supply level of $25 \times 10^{5}, 30 \times 10^{5}, 35 \times 10^{5}, 40 \times 10^{5}$, and $45 \times 10^{5} \mathrm{~m}^{3}$.

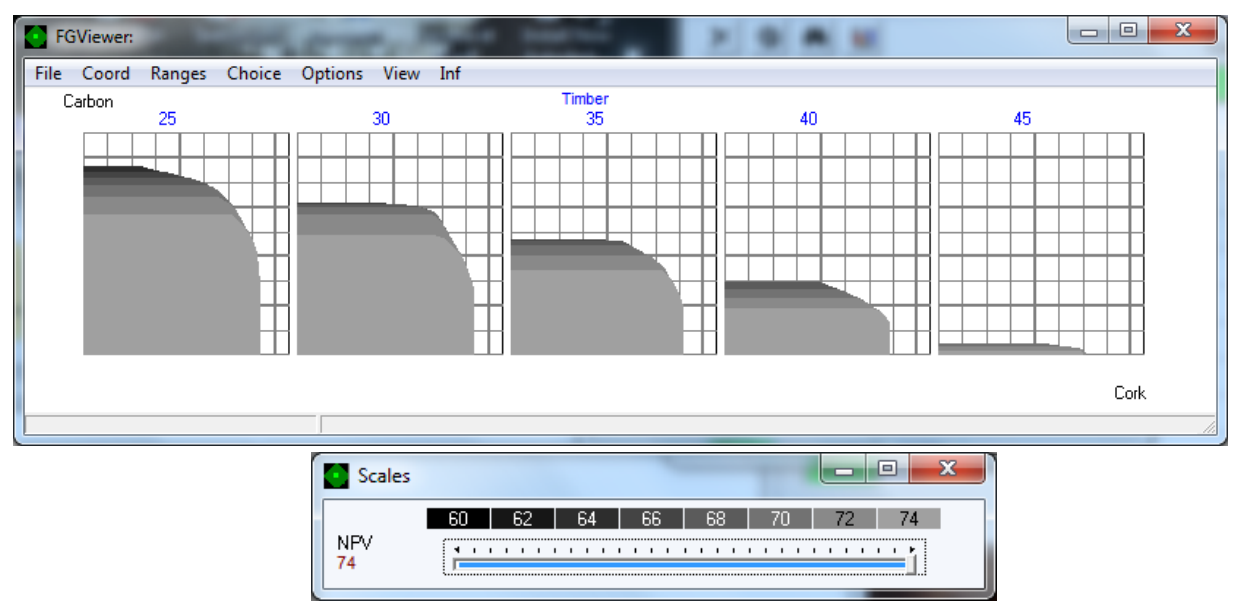

Figure 11. A four-dimensional decision map displaying the efficient frontier of our four-criteria planning problem under a regularity constraint of $30 \%$ in cork supply, considering minimum achievement levels for three criteria (targets for each criterion: min timber $=23.3 \times 10^{4} \mathrm{~m}^{3}$, min cork $=50 \times 10^{7} \mathrm{~kg}$, min Carbon $=24.2 \times 10^{8} \mathrm{~kg}$ ) and a specific achievement level for value for the ending inventory $\left(\mathrm{VEI}=156 \times 10^{7} €\right.$ ). Each decision map corresponds to a specific timber supply level $25 \times 10^{5}, 30 \times 10^{5}, 35 \times 10^{5}, 40 \times 10^{5}$ and $45 \times 10^{5} \mathrm{~m}^{3}$, respectively. The NPV is expressed in $10^{8} €$. 
The system allows DMs to analyze a five-dimensional decision map (a matrix of decision maps) (Figure 12). This matrix contains a series of snapshots of three-dimensional maps. Where every column of the matrix is related to a certain value of the fourth criterion (i.e., VEI) and any row in the matrix is related to a certain value of the fifth criteria (i.e., timber). However, it seems easier to analyze four-dimensional decision maps.



Figure 12. A five-dimensional decision map (a matrix of decision maps) displaying the EPH of our five criteria planning problem considering minimum achievement levels for three criteria (targets for each criterion: $\min$ timber $=23.3 \times 10^{4} \mathrm{~m}^{3}$, min cork $=50 \times 10^{7} \mathrm{~kg}$, min carbon $=24.2 \times 10^{8} \mathrm{~kg}$ ). Each column in the matrix corresponds to a specific timber supply level: $25 \times 10^{4}, 30 \times 10^{4}, 35 \times 10^{4}, 40 \times 10^{4}$, or $45 \times 10^{4} \mathrm{~m}^{3}$. Each row in the matrix corresponds to specific levels of VEI: $150 \times 10^{7}, 153 \times 10^{7}, 156 \times 10^{7}, 159 \times 10^{7}$, and $162 \times 10^{7} €$. 
Decision-makers are mostly concerned with the total amount of revenues, the cork supply as well as with its sustainability. Information provided in Figures 10-12 helped DMs to set the target achievement level for the Timber criteria at $30 \times 10^{4} \mathrm{~m}^{3}$. Then the attention of the DMs focuses on the trade-off analysis between the three other criteria when timber $=30 \times 10^{4} \mathrm{~m}^{3}$ and VEI $=156 \times 10^{7} €$.

The DM may click on the map corresponding the levels of achievement of timber and VEI previously defined (i.e., timber $=3 \times 10^{4} \mathrm{~m}^{3}$ and VEI $=156 \times 10^{7} €$ ) and the system generates the three dimensional decision map which corresponds to all possible combinations of cork, NPV and carbon that leads to the achievement of the minimum achievement levels for timber, carbon and cork supply and for the specific targets fixed for timber and VEI (Figure 13). This information may help the DMs to select the final option.

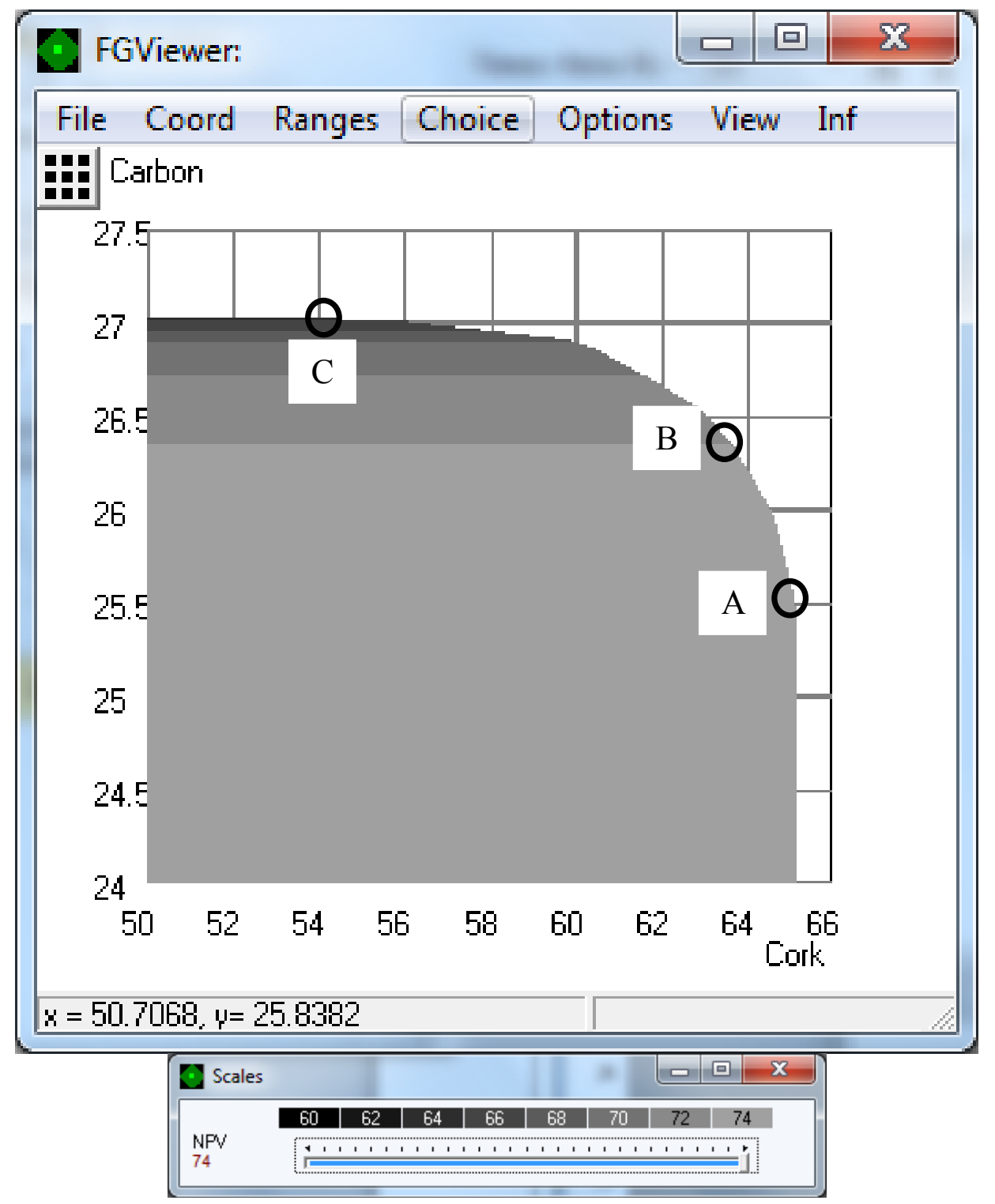

Figure 13. A three-dimensional decision map displaying the EPH of our planning problem, considering minimum achievement levels for two criteria (targets for each criterion: min cork $=50 \times 10^{7} \mathrm{~kg}$, min carbon $=24.2 \times 10^{8} \mathrm{~kg}$ ) and fixed levels of value of ending inventory VEI and timber (i.e., timber $=30 \times 10^{5} \mathrm{~m}^{3}$ and VEI $=156 \times 10^{7} €$ ). The colored area corresponds to different achievement levels of NPV. Points A-C correspond to solutions selected by decision-makers. 
For illustration purposes we present information associated with three choices (points $\mathrm{A}-\mathrm{C}$ in Figure 13), these points correspond to NPV values equal to $74.06 \times 10^{8}, 74 \times 10^{8}$ and $67.93 \times 10^{8} €$. For the solutions timber was equal to $30 \times 10^{4} \mathrm{~m}^{3}$ and VEI was equal to $156 \times 10^{7} €$. The three solutions differed in the values of Carbon and Cork supply. In the case of Carbon the values were 25.5, 25.9 and 26.9 for solutions $\mathrm{A}-\mathrm{C}$, respectively. Cork supply values were $64.6,63.6$ and $58.6 \times 10^{7} \mathrm{~kg}$ for solutions $\mathrm{A}, \mathrm{B}$ and $\mathrm{C}$, respectively. Among all possible points the DM did choose the point B (Figure 13) as this point corresponds to a reasonable combination of the different criteria (Table 1).

By retrieving the values of the levels of achievement of the five goals that were set by the DMs based on the trade-off analysis, the DSS thus generates the information needed to retrieve the solution in the decision space (i.e., the management plan).

Table 1. Solutions in the Feasible Set in the criteria space retrieved by the Reference Point Method (points A-C decision map in Figure 13) for the multi-criteria formulation optimization constrained by a maximum $30 \%$ deviation in periodic adult cork supply.

\begin{tabular}{|c|c|c|c|}
\hline Criteria & Point A & Point B & Point C \\
\hline $\operatorname{NPV}\left(10^{8} €\right)$ & 74.06 & 74.00 & 67.93 \\
\hline \multicolumn{4}{|l|}{ Carbon $\left(10^{8} \mathrm{~kg}\right)$} \\
\hline Period 1 & 19.31 & 19.56 & 20.10 \\
\hline Period 2 & 22.61 & 23.03 & 24.04 \\
\hline Period 3 & 25.94 & 26.50 & 27.71 \\
\hline Period 4 & 28.90 & 29.45 & 30.56 \\
\hline Average & 25.49 & 25.96 & 26.91 \\
\hline \multicolumn{4}{|c|}{ Ad cork $\left(10^{7} \mathrm{~kg}\right)$} \\
\hline Period 1 & 7.49 & 7.47 & 6.96 \\
\hline Period 2 & 9.74 & 9.71 & 9.05 \\
\hline Period 3 & 12.44 & 12.10 & 11.70 \\
\hline Period 4 & 15.17 & 14.94 & 13.43 \\
\hline Period 5 & 19.72 & 19.43 & 17.46 \\
\hline Total & 64.57 & 63.65 & 58.60 \\
\hline \multicolumn{4}{|l|}{ Timber $\left(10^{5} \mathrm{~m}^{3}\right)$} \\
\hline Period 1 & 3.75 & 3.48 & 1.21 \\
\hline Period 2 & 4.41 & 3.74 & 2.10 \\
\hline Period 3 & 4.45 & 4.40 & 4.30 \\
\hline Period 4 & 6.32 & 7.17 & 8.41 \\
\hline Period 5 & 11.13 & 11.46 & 13.98 \\
\hline Total & 30.06 & 30.24 & 30.00 \\
\hline \multicolumn{4}{|c|}{ Disc Revenues $\left(10^{7} €\right)$} \\
\hline Period 1 & 188.40 & 188.08 & 172.71 \\
\hline Period 2 & 167.31 & 167.64 & 154.30 \\
\hline Period 3 & 145.19 & 144.24 & 136.76 \\
\hline Period 4 & 120.85 & 121.25 & 107.64 \\
\hline Period 5 & 103.21 & 103.19 & 92.27 \\
\hline Total & 724.96 & 724.40 & 663.67 \\
\hline $\operatorname{VEI}\left(10^{7} €\right)$ & 156.05 & 156.28 & 156.01 \\
\hline
\end{tabular}




\section{Discussion}

The new DSS functionality was tested using a large scale application - an area in Alentejo in Southern Portugal extending over 1 million ha. Results demonstrated the use of the new DSS integrated functionality. The management information system provided an effective way to store ecosystem data and communicate information to the other DSS modules. The model base efficiently read the ecosystem data to generate prescriptions and simulate the growth of both cork and holm oak over a five-decade planning horizon. The number of cycles varied from 6 to 27. Specifically, after defining cycles, the model base read the inventory data and simulated up to 8400 silviculture strategies for all strata over the 50-year planning horizon. Computational costs were reasonable. The most costly run took about $17 \mathrm{~min}$ in an Intel Core Duo 2.66 MHz machine with $1 \mathrm{~Gb}$ of RAM.

Results further demonstrated the potential of the new DSS integrated functionality to provide decision-makers with information to develop management strategies. The Portuguese Ministry of Agriculture Regional Office of Alentejo (DRAPAL) used an earlier version of the system in 2008 for scenario analysis [31]. However, this version did not include the IDM sub-module to generate Pareto frontiers. The new functionality allows for the assessment of trade-offs between policy analysis criteria and thus it contributes to enhancing policy analysis. Flexibility in linear programming matrix generation within the IDM module is key to this functionality. This system architecture may further be used for enhancing ecosystem management planning.

The trade-offs shown by the new functionality highlighted that NPV and adult cork yield only compete marginally at very high levels of cork production. The highest NPV and the consequent cork production are $79.6108 €$ and $74.43 \times 107 \mathrm{~kg}$. When constraining the solutions to a certain level of regularity of cork availability (allowing cork production to fluctuate between certain levels), a significant decrease in both cork production and NPV is observed. This is due to the inflexibility in cork management as, in order to accomplish the regularity constraints, a large part of the area would remain unmanaged. The results are clearly logical because the profits obtained by debarking trees are much higher than any other possible product (i.e., wood), and there is not any other possible income from the forest. Moreover, the regularity constraint forbids debarking during some years (extent debarking rotation) in order to equilibrate the cork extraction over time, and thus there is a loss of production and profits during the planning period.

The DSS presented in this article provides information on the efficient trade-offs between all the analyzed criteria. It provides information to the user on potentially feasible combinations of values from three to seven criterion values and on efficient criterion trade-offs. This tool may help to overcome the shortcomings of DSS with methods bases that require a priori understanding of the trade-offs between the conflicting criteria such as some multiple-attribute utility methods [32] that involve complicated interactions with DMs - with the latter being required to compare multiple pairs of criteria points before trade-off information is made available. In fact, in the DSS presented no a priori information is asked of the decision-maker about weights of preferences. This is especially important when the DM does not have a clear idea of the feasible values for the different criteria. In fact, one of the main limitations to consider when selecting a particular MCDA approach is the level of available knowledge about the problem space $[18,33]$. Defining a priori the goals and preferences may not be realistic and it may lead to poor management decisions. Thus, the DSS presented here may overcome obstacles of a priori 
preference approaches. The IDM module helps decision-makers specify preferences or targets for the different criteria. Furthermore, it facilitates negotiation when multiple stakeholders are involved in decision-making and policy analysis processes. This is especially important to address complex natural resources management problems where multiple decision-makers and stakeholders are involved.

In the context of multi-criteria optimization Gass et al. [34] proposed to compute and display the Pareto frontier for bi-criteria linear models, approximating the Pareto frontier of the Feasible Set in the Criteria Space (FSCS). At the first stage of this approach, the Pareto frontier is constructed or approximated. At the second stage, the Pareto frontier is represented graphically and then the decision-maker (DM) identifies the most preferable criterion point at this frontier. However, such a convenient method of informing decision-makers was restricted to the bi-criteria problems due to computational difficulties that aroused in multi-dimensional problems. Borges et al. [19] presented and discussed an application of the interactive technique introduced by Lotov et al. [20] to generate the Pareto frontier of forest management planning problems encompassing up to seven objectives. This research developed an effective strategy for integrating this approach in a methods base in a forest ecosystem management and policy analysis decision support system.

Generating and visualizing the complete set of efficient solutions (i.e., Pareto optimal) to planning and policy analysis problems helps the DMs to acquire a holistic view of the planning or policy analysis problem. The new IDM sub-module provides an interactive approach that allows the specification of target criteria levels by the DM on sections of the Pareto frontier [20,35]. The DSS provides the DMs with information about potentially feasible combinations of values from three to seven criteria and about efficient criterion trade-offs. The DMs may identify a preferred feasible combination of criteria values (feasible goals) directly on the graphic display. Then, the computer provides the corresponding solution in the decision space e.g., management plan or behavioral landscape. This allows the DMs to gain insight about ecological, economic, and social interactions, thus generating the information needed for sound policy making.

The system used interactive decision maps in the context of a cork and holm oak forest planning problem where goods and services such as carbon sequestration and cork supply are considered in addition to timber yield. Nevertheless, the system is extensible as it allows for the updating and insertion of production and conservation functions to address other objectives. Future research will focus further on multi-criteria spatial DSS, which may address problems where the spatial context of stand-level decisions must be acknowledged. It will further focus on the development of a web-based architecture of this functionality to support participatory backcasting analysis.

\section{Conclusions}

Results demonstrated the potential of the new DSS integrated functionality to provide decision-makers with information to develop management strategies. The new functionality allows Generating and visualizing the complete set of efficient solutions (i.e., Pareto optimal) to planning and policy analysis problems helping the DMs to acquire a holistic view of the planning or policy analysis problem. It allows for the assessment of trade-offs between policy analysis criteria, which may be very useful to facilitate further communication, cooperation, negotiation, and information sharing between 
stakeholders with a wide range of preferences and interests. This tool contributes to enhancing policy analysis and it may further be used for enhancing ecosystem management planning.

\section{Acknowledgments}

This research was supported by Project PTDC/AGR-FOR/4526/2012 Models and Decision Support Systems for Addressing Risk and Uncertainty in Forest Planning (SADRI), PEst-OE/MAT/UI0117/2014, and it has received funding from the European Union's Seventh Program for research, technological development, and demonstration under grant agreements: I) Nr 282887 INTEGRAL (Future-oriented integrated management of European forest landscapes), II) Nr 226544 MOTIVE (Models for Adaptive Forest Management), and III) Nr PIRSES-GA-2010-269257 (ForEAdapt, FP7-PEOPLE-2010-IRSES).

\section{Author Contributions}

Jordi Garcia-Gonzalo was responsible for coding part of the DSS, writing the article, and performing the computations and the analysis of data. Vladimir Bushenkov was responsible for coding part of the DSS and editing the article, as well as giving advice during the development of the DSS. José G. Borges and Marc McDill helped in writing the article, analyzing results, and giving advice during the development of the DSS.

\section{Conflicts of Interest}

The authors declare no conflict of interest.

\section{References}

1. Reynolds, K.M.; Borges, J.G.; Vacik, H.; Lexer, M.J. Information and communication technology in forest management and conservation. In Information Technology and the Forest Sector, IUFRO World Series; Hetemaki, L., Nilsson, S., Eds.; International Union of Forest Research Organizations: Vienna, Austria, 2005; Volume 18, pp. 150-171.

2. Eriksson, L.O.; Borges, J.G.; Vacik, H.; Lexer, M.J.; Scholz, J.; Wolfslehner, B.; Köck, A.M.; Granitzer, M.; Rodriguez, L.C.E.; Nobre, S.R.; et al. Computer-Based Tools for Supporting Forest Management. The Experience and the Expertise World-Wide; Borges, J.G., Nordström, E.M., Garcia-Gonzalo, J., Hujala, T., Trasobares, A., Eds.; Department of Forest Resource Management, Swedish University of Agricultural Sciences: Umeå, Sweden, 2014.

3. Reynolds, K.M.; Twery, M.; Lexer, M.J.; Vacik, H.; Ray, D.; Shao, G.; Borges, J.G. Decision support systems in natural resource management. In Handbook on Decision Support Systems; Burstein, F., Holsapple, C., Eds.; Springer-Verlag: Berlin, Germany, 2008; Volume 2, pp. 499-534.

4. Borges, J.G.; Oliveira, A.C.; Costa, M.A. A quantitative approach to cork oak forest management. For. Ecol. Manag. 1997, 97, 223-229.

5. Diaz-Balteiro, L.; Romero, C. Making forestry decisions with multiple criteria: A review and an assessment. For. Ecol. Manag. 2008, 255, 3222-3241. 
6. Falcão, A.; Borges, J.G. Designing decision support tools for Mediterranean forest ecosystems management: A case study in Portugal. Ann. For. Sci. 2005, 62, 751-760.

7. Garcia-Gonzalo, J.; Pukkala, T.; Borges, J. Integrating fire risk in stand management scheduling. An application to Maritime pine stands in Portugal. Ann. Oper. Res. 2014, 219, 379-395.

8. Gonzalez, J.; Palahi, M.; Pukkala, T. Integrating fire risk considerations in forest management planning in Spain-A landscape level perspective. Landsc. Ecol. 2005, 20, 957-970.

9. Palahí, M.; Pukkala, T. Optimising the management of Scots pine (Pinus sylvestris L.) stands in Spain based on individual-tree models. Ann. For. Sci. 2003, 60, 105-114.

10. Palahí, M.; Pukkala, T.; Pascual, L.; Trasobares, A. Examining alternative landscape metrics in ecological forest landscape planning: A case for capercaillie in Catalonia. Investig. Agrar. Sist. Recur. For. 2004, 13, 527-538.

11. Ribeiro, R.P.; Borges, J.G.; Oliveira, V. A framework for data quality for Mediterranean sustainable ecosystem management. Ann. For. Sci. 2004, 61, 557-568.

12. Marques, A.F.; Garcia-Gonzalo, J.; Borges, J.G. Computer-based tools for supporting forest management in Portugal. In Computer-Based Tools for Supporting Forest Management. The Experience and the Expertise World-Wide; Borges, J.G., Nordstrom, E., Garcia-Gonzalo, J., Hujala, T., Trasobares, A., Eds.; Department of Forest Resource Management, Swedish University of Agricultural Sciences: Umeå, Sweden, 2014; pp. 296-319.

13. Borges, J.G.; Falcão, A.O.; Miragaia, C.; Marques, P.; Marques, M. A decision support system for forest ecosystem management in Portugal. In Systems Analysis in Forest Resources; Arthaud, G.J., Barrett, T.M., Eds.; Kluwer Academic Publishers: Dordrecht, the Netherlands, 2003; Volume 6, pp. 155-163.

14. Marques, S.; Borges, J.G. Relatório de Execução do Sistema de Gestão de Informação INfLOR 2.1; Departamento de Engenharia Florestal: Lisboa, Portugal, 2007; p. 23.

15. Marques, A.F.; Borges, J.G.; Garcia-Gonzalo, J.; Lucas, B.; Melo, I. A participatory approach to design a toolbox to support forest management planning at regional level. For. Syst. 2013, 22, 340-358.

16. Grimble, R.; Wellard, K. Stakeholder Methodologies in Natural Resource Management: A Review of Principles, Contexts, Experiences and Opportunities. Agric. Syst. 1997, 55, 173-193.

17. Martins, H.; Borges, J.G. Addressing collaborative planning methods and tools in forest management. For. Ecol. Manag. 2007, 248, 107-118.

18. Huang, I.; Keisler, J.; Linkov, I. Multi-criteria decision analysis in environmental sciences: Ten years of applications and trends. Sci. Total Environ. 2011, 409, 3578-3594.

19. Borges, J.G.; Garcia-Gonzalo, J.; Bushenkov, V.A.; McDill, M.E.; Marques, S.; Oliveira, M.M. Addressing multi-criteria forest management with Pareto Frontier methods: An application in Portugal. For. Sci. 2014, 60, 63-72.

20. Lotov, A.V.; Bushenkov, V.A.; Kamenev, G.K. Interactive Decision Maps; Kluwer Academic Publishers: New York, NY, USA, 2004.

21. Lotov, A.V.; Miettinen, K. Visualizing the pareto frontier. In Multiobjective Optimization; Branke, J., Deb, K., Miettinen, K., Slowinski, R., Eds.; Springer Berlin Heidelberg: New York, NY, USA, 2008; pp. 213-243. 
22. Tomé, M.; Coelho, M.B.; Pereira, H.; Lopes, F. A management oriented growth and yield model for cork oak stands in Portugal. In Proceedings of the IUFRO Workshop Empirical and Process Based Models for Forest Tree and Stand Growth Simulation, Oeiras, Portugal, 21-27 September 1997; Amaro, A., Tomé, M., Eds.; Novas Tecnologias: Oeiras, Portugal, 1999; pp. 271-289.

23. Miragaia, C.; Borges, J.G.; Falcao, A.; Tomé, M. InFlor, a management information system of forest resources. In Modelling the Growth of Tree Plantations and Agroforestry Systems in South and East Africa; Faculty of Forestry Research Notes 80; Pukkala, T., Eerikainen, K., Eds.; University of Joensuu: Joensuu, Finland, 1998; pp. 131-142.

24. Davis, L.S.; Johnson, K.N.; Howard, T.; Bettinger, P. Forest Management; McGraw Hill Publishing Company: New York, NY, USA, 2001.

25. Bushenkov, V.A.; Lotov, A.V. Methods for the Construction and Application of Generalized Reachable Sets; Computing Center of the USSR Academy of Sciences: Moscow, Russian, 1982; p. 54.

26. Bushenkov, V.A. An iteration method of constructing orthogonal projections of convex polyhedral sets. U.S.S.R. Comput. Maths. Math. Phys. 1985, 25, 1-5.

27. Chernykh, O.L. Construction of the convex hull of a finite set of points then the computations are approximate. U.S.S.R. Comput. Maths. Math. Phys. 1988, 28, 71-77.

28. Chernykh, O.L. Approximation of the Pareto-hull of a convex set by polyhedral sets. Comput. Maths. Math. Phys. 1995, 35, 1033-1039.

29. Wierzbicki, A. A mathematical basis for satisficing decision making. In Organizations: Multiple Agents with Multiple Criteria; Morse, J., Ed.; Springer: Berlin, Germany, 1981; pp. 465-485.

30. Johnson, K.N.; Scheurman, H.L. Techniques for prescribing optimal timber harvest and investment under different objectives: Discussion and synthesis. For. Sci. Monogr. 1977, 18, 31.

31. Borges, P.; Marques, S.; Borges, J.G.; Tomé, M. Scenario analysis applied to cork and holm oak forest ecosystems in Southern Portugal. In Modelling, Valuing and Managing Mediterranean Forest Ecosystem for Non-Timber Goods and Services; Palahi, M., Birot, Y., Bravo, F., Gorris, E., Eds.; European Forest Institute: Joensuu, Finland, 2009; Volume 57, pp. 49-56.

32. Keeney, R.; Raiffa, D.H. Decisions with Multiple Objectives: Preferences and Value Trade-Offs; John Wiley and Sons, Inc.: New York, NY, USA, 1976; p. 569.

33. Linkov, I.; Moberg, E. Multi-Criteria Decision Analysis: Environmental Applications and Case Studies; CRC Press: Boca Raton, FL, USA, 2012.

34. Gass, S.; Saaty, T. The computational algorithm for the parametric objective function. Nav. Res. Logist. Q. 1955, 2, 39-51.

35. Miettinen, K. Nonlinear Multiobjective Optimization; Springer Science + Business Media: New York, NY, USA, 1998.

(C) 2014 by the authors; licensee MDPI, Basel, Switzerland. This article is an open access article distributed under the terms and conditions of the Creative Commons Attribution license (http://creativecommons.org/licenses/by/4.0/). 